\title{
Infant suffocation while breastfeeding
}

\author{
Roger W. Byard ${ }^{1,2,3}$
}

Accepted: 5 February 2020 / Published online: 3 March 2020

(C) Springer Science+Business Media, LLC, part of Springer Nature 2020

Death while being breastfed forms a specific subset of shared sleeping fatalities [1]. One of the concerns which initiated this original study was that two infants had died during breastfeeding in the post-neonatal ward of a local hospital. As the first death had been incorrectly called sudden infant death syndrome (SIDS) no steps were taken to increase the monitoring of exhausted mothers while in hospital care. The second death was, however, correctly attributed to suffocation as the infant had been found dead underneath and facing into the sleeping mother's large breast. Following this autopsy conclusion, ward protocols were changed and no further deaths have occurred in the ensuing decades. This provides an excellent illustration of the usefulness that medicolegal investigations by pathologists may have in preventing deaths.

There has been a very strong tendency for researchers to lump all infant deaths under the rubric of SIDS. This was exemplified by recent papers where all infant deaths in shared sleeping environments were called SIDS, including cases where the deaths occurred on the narrow, sloped and soft surfaces of a sofa/couch that was being shared with an adult [2-4]. The lack of acknowledgment that at least some of these cases must be due to suffocation is of concern. Certainly the differentiation of suffocation from SIDS has been difficult with the previous markers for asphyxia such as liquid blood and petechiae being now recognised as being quite unreliable $[5,6]$.

An important development in recent years, however, has been the demonstration that infants who die in shared sleeping situations are different epidemiologically and pathologically

Roger W. Byard

roger.byard@sa.gov.au

Forensic Science SA, 21 Divett Place, Adelaide 5000, Australia

2 Discipline of Anatomy and Pathology, The University of Adelaide, Frome Road, Level 2 Helen Mayo Building North,

Adelaide, SA 5005, Australia

3 Adelaide Medical School, The University of Adelaide, Frome Road, Level 3 Medical School North Building, Adelaide, SA 5005, Australia to those who die on their own i.e. classic SIDS deaths [7]. The male to female ratio is similar in shared sleepers demonstrating that for some reason there is a significantly higher number of girls than typical SIDS populations [8]. In addition, it has been shown that shared sleepers have increased number of circulating normoblasts which may represent a response to hypoxia [9]. Other studies have shown an array of neuropathological differences in alone sleepers compared to shared sleepers including higher levels of terminal deoxynucleotidyl transferase-mediated dUTP nick-end labelling (TUNEL), $\beta$ amyloid precursor protein ( $\beta$-APP) and glial fibrillary acidic protein (GFAP) [10-12].

It should also be noted that certain infants may be particularly sensitive to airway obstruction and cases have been reported where infants stopped breathing quite quickly while simply being cradled against an awake family member's breast. In this situation breast-related airway obstruction had occurred without feeding. In another case an infant suffocated during breastfeeding when her mother had been distracted by a sibling's activities outdoors [13].

While it has been stated that the risk of accidental suffocation in bed sharing infants who are being breast fed is "extremely rare" in the absence of "hazardous circumstances" [4], it could be suggested that the very nature of this activity in bed is a potential hazard [14, 15], particularly with recent increases in body mass index in many communities $[16,17]$. The reality is that any tired or intoxicated mother who is breastfeeding in bed is at risk of falling asleep and causing lethal obstruction of her infant's airway. Until we can determine the significance of the recently identified neuropathological markers in these infants and evaluate larger study groups, the exact numbers of these deaths will probably remain unknown. Death during breastfeeding should, however, be recognised and recorded when an infant is found deceased with his/her mouth and nose covered by a soft, indentable breast when a mother has fallen asleep while breastfeeding. This will assist in determining the true incidence and increase our understanding of this entity without these deaths become de-identified by being grouped in with genuine SIDS cases. 
Bed sharing and breast feeding are certainly not to be demonised, however, the identification and study of yet another subgroup of sudden and unexpected infant deaths will assist us in appreciating the complexity of different circumstances and underlying pathophysiological processes. This will then hopefully lead to further steps to prevent such tragic events.

\section{References}

1. Byard RW. Is breast feeding in bed always a safe practice? J Paediatr Child Health. 1998;34:418-9.

2. Carpenter R, McGarvey C, Mitchell EA, Tappin DM, Vennemann MM, Smuk M, et al. Bed sharing when parents do not smoke: is there a risk of SIDS? An individual level analysis of five major case-control studies. BMJ Open. 2013;3:e02299.

3. Venneman MM, Hense HW, Bajanowski T, Blair PS, Complojer C, Moon RY, et al. Bed sharing and risk of sudden infant death syndrome: can we resolve the debate? J Pediatr. 2012;160:44-8.

4. Blair PS, Ball HL, McKenna JJ, Feldman-Winter L, Marinelli KA, Bartick MC, et al. Bedsharing and breastfeeding: The Academy of Breastfeeding Medicine Protocol \#6, Revision 2019. Breastfeed Med. 2020;15:5-16.

5. Beal SM, Byard RW. Accidental death or sudden infant death syndrome? J Paediatr Child Health. 1995;31:269-71.

6. Byard RW, Krous HF, editors. Sudden infant death syndrome problems, progress and Possibilities. London: Arnold; 2001.

7. Collins-Praino L, Byard RW. Infants who die in shared sleeping situations differ from those who die sleeping alone. Acta Paediatr. 2019;108:611-4.
8. Byard RW, Elliott J, Vink R. Infant gender, shared sleeping and sudden death. J Paediatr Child Health. 2012;48:517-9.

9. Cohen MC, Yong CY, Evans C, Hinchliffe R, Zapata-Vazquez RE. Release of erythroblasts to the peripheral blood suggests higher exposure to hypoxia in cases of SIDS with co-sleeping compared to SIDS non-co-sleeping. Forensic Sci Int. 2010;197:54-8.

10. Machaalani R, Waters KA. Neuronal cell death in the sudden infant death syndrome brainstem and associations with risk factors. Brain. 2008;131(Pt 1):218-28.

11. Jensen LL, Banner J, Byard RW. Does $\beta$-APP staining of the brain in infant bed sharing deaths differentiate these cases from sudden infant death syndrome? J Forensic Leg Med. 2014;27:46-9.

12. Spinelli J, Byard RW, Van Den Heuvel C, Collins-Praino L. Medullary astrogliosis in sudden infant death syndrome varies with sleeping environment: evidence for different mechanisms of death in alone verses co-sleepers? J Child Neurol. 2018;33:269-74.

13. Byard RW, Burnell RH. Apparent life threatening events, and infant holding practices. Arch Dis Child. 1995;73:502-4.

14. Byard RW. Is co-sleeping in infancy a desirable or dangerous practice? J Paediatr Child Health. 1994;30:198-9.

15. Byard RW. Overlaying, co-sleeping, suffocation, and sudden infant death syndrome - the elephant in the room. Forensic Sci Med Pathol. 2015;11:273-4.

16. Corder K, Winpenny EM, Foubister C, Guagliano JM, Hartwig $\mathrm{XM}$, Love R, et al. Becoming a parent: A systematic review and meta-analysis of changes in BMI, diet, and physical activity. Obes Rev. 2020. https://doi.org/10.1111/obr.12959.

17. Byard RW. The complex spectrum of forensic issues arising from obesity. Forensic Sci Med Pathol. 2012;8:402-13.

Publisher's note Springer Nature remains neutral with regard to jurisdictional claims in published maps and institutional affiliations. 